\title{
A six-year retrospective study of maxillofacial fractures from radiographic findings in Brazil
}

\author{
Estudo retrospectivo de seis anos de fraturas maxilofaciais provenientes \\ de achados radiográficos realizado no Brasil
}

\author{
Mayco Aurélio Somensi* \\ Aline de Oliveira Gonçalves* \\ Cláudia Maria Navarro* \\ Eduardo Hochuli Vieira** \\ Andréa Gonçalves**
}

\section{Abstract}

Objective: this study aimed to present the causes and prevalence of maxillofacial fractures that occurred in the region of Araraquara-SP - Brazil, during a 6-year period. Methods: information regarding age, gender, etiology, and maxillofacial fracture site, as well as type of radiographic examination were evaluated. Data were gathered from the radiographic examination and radiographic report of the Division of Dentomaxillofacial Radiology, and from charts of the Division of Oral and Maxillofacial Surgery of patients attending for maxillofacial fractures from 2004 to 2009. A descriptive statistical analysis was developed using Epi-Info 3.5.1. Results: from a total of 11,728 patients assisted, 407 patients presented maxillofacial fractures. The prevalent age ranged from 21 to 30 years old. From the total patients, 322 were men and 85 were women (ratio of men to women was 3.8:1). Panoramic radiography $(n=306)$ was most frequently used to observe maxillofacial fractures. Mandibular fractures were frequent in the body of the mandible $(n=127)$, followed by symphysis $(n=$ 102), and the prevalent cause was traffic accidents ( $n=$ 161). Conclusion: more than half of affected individuals were younger than 40 years of age. The body of the mandible was the most common fracture location visualized by panoramic radiography for traffic accidents and fights.

Keywords: Fractures. Epidemiology. Retrospective studies.

\section{Introduction}

Maxillofacial injuries represent one of the most important health problems worldwide ${ }^{1}$ and vary from country to country ${ }^{2}$. The epidemiology of facial fractures varies according to the type, severity, and cause of injury, depending on the population studied $^{3}$. The patterns of maxillofacial fracture presentation are consistently influenced by geographic area, environment, gender, age, socioeconomic status of the patient, and the period of the investigation $^{1,2,4}$. According to reports from developing countries, road accidents are the predominant cause of maxillofacial injuries ${ }^{1,5-7}$, while data from developed countries suggest assaults as the most frequent etiology of such fractures ${ }^{1,5,8-10}$.

The coordinated and sequential collection of information concerning demographic patterns of maxillofacial injuries may assist healthcare providers to record details and data from facial traumas. Consequently, an understanding of the cause, severity, and temporal distribution of maxillofacial trauma allows clinical and research priorities to be established for effective treatment and prevention of these injuries ${ }^{1}$.

A clearer understanding of the demographic patterns of maxillofacial injuries will assist healthcare providers as they plan and manage the tre-

DDS, Araraquara Dental School, Universidade Estadual Paulista (Unesp), Araraquara, SP, Brazil.

DDS, PhD, professor, Araraquara Dental School, Universidade Estadual Paulista (Unesp), SP, Araraquara, Brazil. 
atment of traumatic maxillofacial injuries ${ }^{2,11}$. Continuous long-term collection of data regarding the epidemiology of maxillofacial fractures is important because it provides information necessary for the development and evaluation of preventive measures to reduce the incidence of facial injuries ${ }^{3}$.

Few specific epidemiologic reports about maxillofacial fractures in South America are available in literature. Therefore, data were collected from radiographic reports of different radiographic techniques to obtain information about maxillofacial injuries. The present study aimed to present the causes and prevalence of maxillofacial fractures over a 6-year period at Dental School.

\section{Methods}

This study was approved by the Ethics in $\mathrm{Hu}-$ man Research Committee of the Dental School (protocol no. 11/09). This 6-year retrospective epidemiological study was performed among 11,728 patients who attended the Division of Dentomaxillofacial Radiology and the Division of Oral and Maxillofacial Surgery at a Dental School. The Division of Oral and Maxillofacial Surgery provides maxillofacial trauma referrals for the entire population of Araraquara and outside region, a population of approximately 1 million inhabitants.

This study involved the review of radiographic examinations and respective reports of patients who attended the Division of Dentomaxillofacial Radiology from January 2004 to December 2009, and a review of charts from the Division of Oral and Maxillofacial Surgery to determine the cause of fracture and confirm the site, when required. All patients with maxillofacial fractures and prevalence of fractures $(n=407)$ were included; other patients who attended the Dentomaxillofacial Radiology clinic, but did not present maxillofacial fractures and patients who received orthognathic surgery were excluded. Our form included an item that indicated whether the patient had received treatment or not, considering that the first care of patients with fractures most often occurred in the hospital by a team of professors of the Division of Oral and Ma- xillofacial Surgery, where computed tomography is available. Thereby the immediate postoperative period and the control postoperative period were performed at the Dental School and these data were in the patient' charts, including the anatomic site of injuries. The variables analyzed included age, gender, anatomic site of injuries, type of radiographic examination, and cause of maxillofacial fracture. The radiographs verifying maxillofacial injuries were requested from the Division of Dentomaxillofacial Radiology to evaluate the patient before and after surgical treatment. Data were collected on forms and then typed; calculation results were performed by means of Epi Info 3.5.1 software. The statistical analysis involved descriptive statistics.

\section{Results}

In the 6 years of this study, from a total of 11,728 patients who attended the Dentomaxillofacial Radiology Division, 407 patients presented maxillofacial fractures: 322 patients were male $(79.1 \%)$ and 85 patients were female $(20.9 \%)$, and the ratio of men to women was 3.8:1.

Patients ranged from 1 to 90 years of age, with mean age ranging from 21 to 30 years old $(\mathrm{n}=122)$, followed by 31 to 40 years old ( $n=88$ ), considering the prevalence of men in all studied age groups.

The radiography most frequently used to visualize maxillofacial trauma was the panoramic radiography (46.5\%), followed by Waters' projection of the skull (18.5\%), and the submentovertex projection $(11.9 \%)$.

The most frequent cause of maxillofacial injuries (Table 1) for both genders was traffic accidents $(39.6 \%)$, followed by fights $(21.6 \%)$. In women, the second most frequent cause was falls (22.4\%). With regards to specific information about traffic accidents, automobile accidents (39.1\%), followed by motorcycle accidents $(30.4 \%)$, were the most frequent for both genders. It should be pointed out that the number of women in traffic accidents $(\mathrm{n}=$ 36) was inferior to that of the number of men who were involved in motorcycle accidents $(n=39)$, which was ranked in the second place of occurrence.

Table 1 - Distribution of the causes of maxillofacial fractures, according to gender

\begin{tabular}{|c|c|c|c|c|c|c|}
\hline \multirow{2}{*}{ Causes } & \multicolumn{2}{|c|}{ Male } & \multicolumn{2}{|c|}{ Female } & \multicolumn{2}{|c|}{ Total } \\
\hline & $\mathrm{n}$ & $\%$ & $\mathrm{n}$ & $\%$ & $\mathrm{n}$ & $\%$ \\
\hline Traffic accident & 125 & 38.8 & 36 & 42.4 & 161 & 39.6 \\
\hline Fights & 74 & 23.0 & 14 & 16.5 & 88 & 21.6 \\
\hline Other & 54 & 16.8 & 15 & 17.6 & 69 & 17.0 \\
\hline Falls & 27 & 8.4 & 19 & 22.4 & 46 & 11.3 \\
\hline Work accident & 15 & 4.7 & 0 & 0.0 & 15 & 3.7 \\
\hline Gunshot & 11 & 3.4 & 1 & 1.2 & 12 & 3.0 \\
\hline Sport accident & 9 & 2.8 & 0 & 0.0 & 9 & 2.2 \\
\hline Animal accident & 6 & 1.9 & 0 & 0.0 & 6 & 1.5 \\
\hline Surgical accident & 1 & 0.3 & 0 & 0.0 & 1 & 0.3 \\
\hline Total & 322 & 100 & 85 & 100 & 407 & 100 \\
\hline
\end{tabular}


With regards to the distribution of maxillofacial fractures $(n=927), 464$ fractures occurred in the mandible, while 463 fractures occurred in the maxilla, middle third of face, and elsewhere. Considering that panoramic radiography (Table 2, Figures 1 and 2) was the most requested radiography, a study was made on the distribution of the location of maxillofacial fractures in this radiographic examination $(n=687)$. The most frequent site observed was the body of the mandible (18\%).

Table 2 - Distribution of maxillofacial fractures sites visualized in panoramic radiography

\begin{tabular}{l|c|c}
\hline \multirow{2}{*}{\multicolumn{1}{c}{ Fracture site }} & \multicolumn{2}{c}{ Total } \\
\cline { 2 - 3 } & $\mathrm{n}$ & $\%$ \\
\hline Body of the mandible & 124 & 18.0 \\
Symphysis & 99 & 14.4 \\
Condyle & 86 & 12.5 \\
Orbital cavity & 85 & 12.4 \\
Angle of the mandible & 70 & 10.2 \\
Middle third of the face & 68 & 9.9 \\
Zygomatic bone & 60 & 8.7 \\
Ramus of the mandible & 48 & 7.0 \\
Dentoalveolar process in mandible & 19 & 2.8 \\
Anterior region of maxilla & 13 & 1.9 \\
Dentoalveolar process in maxilla & 10 & 1.5 \\
Coronoid process & 5 & 0.7 \\
Total & 687 & 100 \\
\hline
\end{tabular}

As seen in Table 3, traffic accidents $(n=238)$ were the most frequent cause of sites of maxillofacial injuries, followed by fights $(n=110)$. Animal accidents caused only injuries in the body of the mandible and the zygomatic bone ( $\mathrm{n}=4$ and $\mathrm{n}=1$, respectively). When panoramic radiography was considered, traffic accidents were also ranked as the most frequent cause, which included motorcycle, automobile, and bicycle accidents, and pedestrian-motor vehicle accidents (MVA). When symphysis was prevalent on panoramic radiography, motorcycle accidents $(\mathrm{n}=15)$, followed by automobile $(\mathrm{n}=13)$ and bicycle $(\mathrm{n}=13)$ accidents were observed.

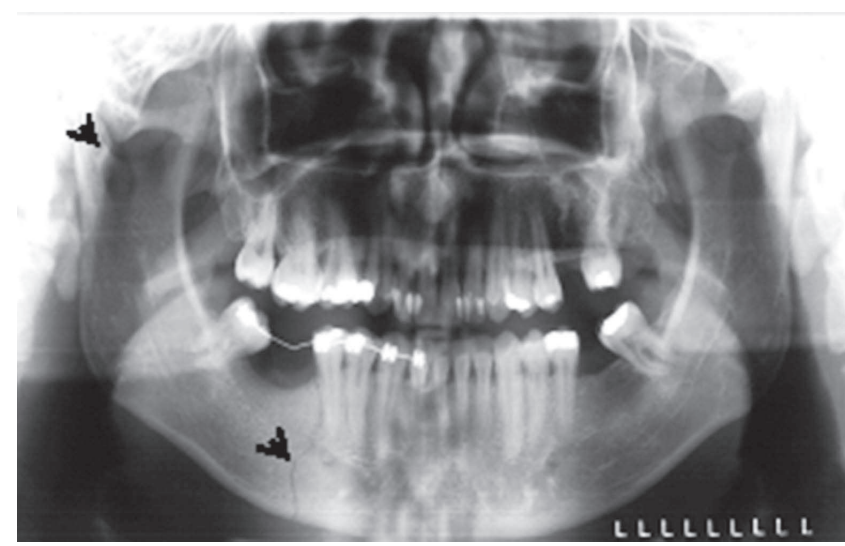

Figure 1 - Panoramic radiography showing right body of mandible and condyle fractures
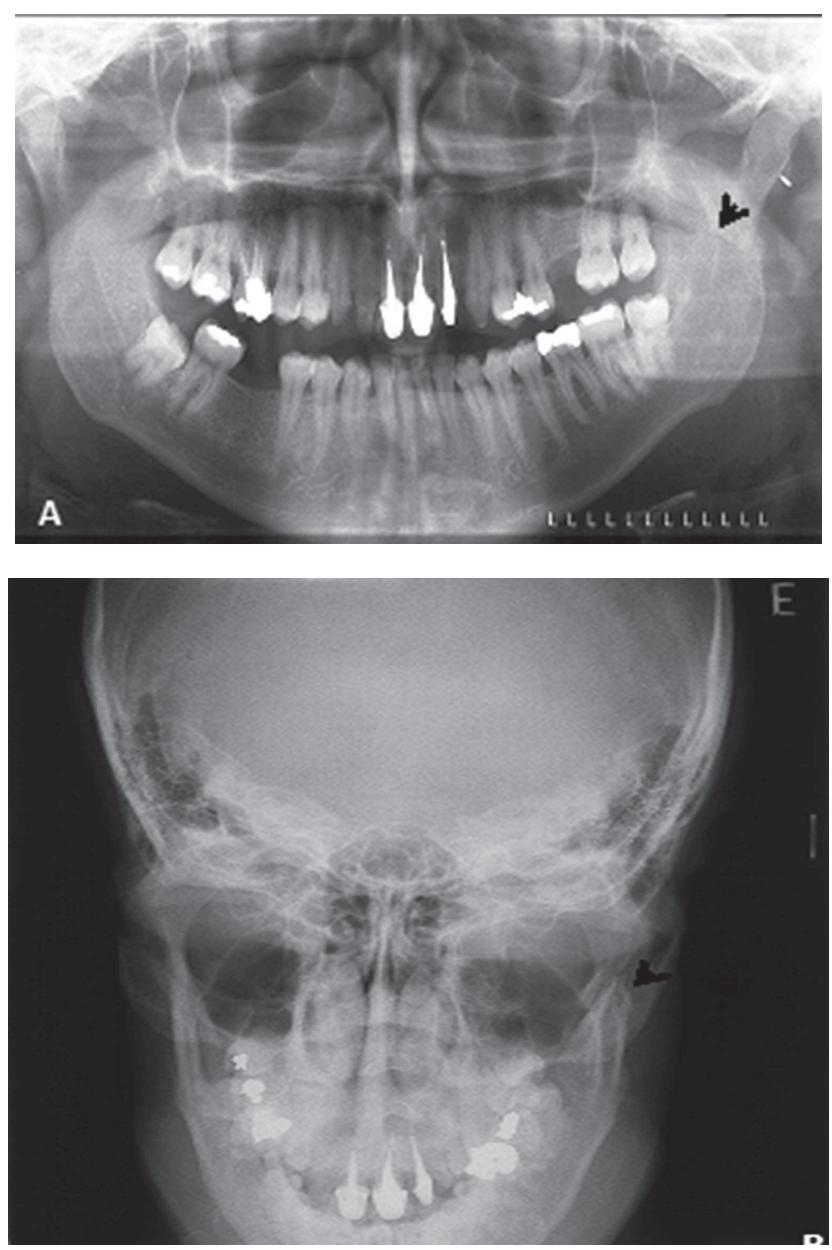

Figure 2 - Left condyle fracture showed by panoramic radiography and anteroposterior Towne's projection of the skull

Table 3 - Frequency of the causes of maxillofacial fractures according to site

\begin{tabular}{|c|c|c|c|c|c|c|c|c|c|c|c|}
\hline & $\begin{array}{l}\text { Automobile } \\
\text { accidents }\end{array}$ & $\begin{array}{c}\text { Motorcycle } \\
\text { accidents }\end{array}$ & $\begin{array}{c}\text { Bicycle } \\
\text { accidents }\end{array}$ & MVA & Fights & Unknown & Falls & $\begin{array}{c}\text { Work } \\
\text { accidents }\end{array}$ & $\begin{array}{c}\text { Sport } \\
\text { accidents }\end{array}$ & Gunshot & $\begin{array}{c}\text { Animal } \\
\text { accidents }\end{array}$ \\
\hline Orbital cavity & 40 & 25 & 15 & 2 & 33 & 16 & 10 & 8 & 5 & 1 & 0 \\
\hline Body of mandible & 12 & 18 & 13 & 2 & 30 & 23 & 7 & 6 & 2 & 4 & 4 \\
\hline Zygomatic bone & 24 & 15 & 13 & 2 & 23 & 16 & 6 & 8 & 5 & 3 & 1 \\
\hline $\begin{array}{l}\text { Middle third of the } \\
\text { face }\end{array}$ & 28 & 18 & 9 & 2 & 24 & 11 & 9 & 5 & 4 & 2 & 0 \\
\hline Total & 104 & 76 & 50 & 8 & 110 & 66 & 32 & 27 & 16 & 10 & 5 \\
\hline
\end{tabular}


Traffic accidents $(43.4 \%)$ were the main cause of injuries for both genders, from 21 to 30 years old. Animals (3.1\%), sport (4.1\%), and work (2\%) accidents were injury types only observed for men. Fights $(22.7 \%$; $16 \%)$, others $(15.4 \% ; 20 \%)$, gunshots $(5.1 \% ; 4 \%)$, and falls $(6.2 \% ; 8 \%)$ were found in men and women, respectively.

For the prevalent age group, motorcycle accidents $(43.4 \%)$ were the most common cause for men and women, followed by automobile accidents $(39.6 \%)$ and bicycle accidents $(13.2 \%)$. The pedestrian-motor vehicle accidents occurred in one man and one woman.

\section{Discussion}

This study covered a period from 2004 to 2009 in the region of Araraquara-SP, located in southeast Brazil, with more than half the population being younger than 40 years old, and a ratio of women to men of 1.06:1. This epidemiological survey involving a majority of men (3.8:1) with fractures was similar to results of other reports ${ }^{1-28}$. The age group most affected was from 21 to 40 years old, suggesting intense social interaction and a period that is influenced by high alcohol-consumption, unemployment, and a period of reduced economic activity ${ }^{12}$, and because men are more involved in traffic accidents $^{3}$.

It is interesting to observe how the cultural and social-economic characteristics of the population studied may influence the incidence of maxillofacial fractures in women. Work, sport, animals, and surgical accidents were not causes of injuries for women in this investigation; however, $17.6 \%$ of maxillofacial fractures were observed to have unknown etiology in women. In the charts examined, when the cause of injury was either not recorded or unknown, it was considered as an unknown cause. It may be considered that this percentage and the occurrence in the 21 to 30 year-old-group as the peak incidence because women omitted the cause of injury when they were beaten.

Only three surveys carried out in Brazil - this study, $1.9 \%$; Gabrielli et al. ${ }^{13}$ (2003), 2.62\%; Batista et al. ${ }^{.9}$ (2012), $14.1 \%$ - mention animal accidents as causes of these fractures; the possible explanation for this is that the other reports consider animal accidents as being grouped as other causes or they did not find this etiology for maxillofacial fracture.

More than half of this study sample was younger than 40 years of age. Both men and women presented in the 21 to 30 year-old-group as the peak incidence of maxillofacial fractures. Age distribution of the patients in the present study is consistent with previous findings ${ }^{1,2,5-8,10-24,26-28}$. The possible explanation for this is that the population of this age group frequently participates in outdoor activities and dangerous sports, may be careless drivers, and demonstrates violent interactions ${ }^{7}$.

Traffic accidents are still the main cause of maxillofacial fractures in developing countries ${ }^{1,5-7,13,22,26}$ and in some developed countries ${ }^{15,17,20,21,28}$. The mean speed limit in the region of Araraquara of 50 $\mathrm{km} / \mathrm{h}$ follows the national road traffic legislation. In Brazil, the use of seatbelts is mandatory and local authorities have encouraged the enforcement of existing traffic laws. Traffic accidents were the prevalent cause of maxillofacial fractures in this study involving 125 (38.8\%) men and 36 (42.4\%) women, as earlier studies have also shown ${ }^{1,5-7,11,13,15,17,20-23,27,28}$. The type of traffic accident (automobile, motorcycle, and pedestrian) requires attention, especially motorcycle accidents, because these are important means of transportation in the region of Araraquara and provided a significant number of cases $(30.4 \%)$ in this survey. A previous study ${ }^{3}$ revealed that alcohol contributed not only to increased violence, but it also was an important contributing factor in motor vehicle accidents. Data on alcohol consumption could not be obtained in this study, as the patients' charts did not contain such data. When the etiology of the fracture is known, it is possible to take the necessary steps or record protocols for special age groups, which may help to avoid maxillofacial injury.

In urban centers of developed countries ${ }^{8-10,14,16,19,23}$ and developing countries ${ }^{12,24}$, violence was reported to be the most common cause of injury, as well as in another report ${ }^{4}$ that studied a population of $<18$ years of age. In the present study, violence was evaluated as fighting and gunshot wounds (24.6\%). In 2008, the drink-drive law and programs to reduce road accidents were introduced, and it may be assumed that this percentage will increase in the future if traffic accidents decrease.

Maxillofacial fractures were more common in the mandible, in this study $(50.2 \%)$ and previous reports $^{1,4-7,9,10,13-15,21,25,28}$. In this survey, the most frequent site of maxillofacial fracture visualized by panoramic radiography was the body of the mandible (18\%), similar results were found by other stu$\operatorname{dies}^{5,6,24,28}$. Some sites of maxillofacial injuries - for instance, the orbital cavity - that were found by panoramic radiography (Table 2) may be explained by the fact that the panoramic radiography was not always read alone, but read along with other extraoral radiographs. Furthermore, the patients' charts and the titanium mesh plates confirmed the location of the fracture.

\section{Conclusions}

The present study was an epidemiological evaluation of maxillofacial fractures that investigated the prevalence and cause of these injuries. Data 
demonstrated trauma patterns for the studied population and may aid in formulating preventive programs and treatment. Thus, in conclusion, men were more affected by maxillofacial fractures; the prevalent age group was from 21 to 30 years old. The panoramic radiography was most requested for the visualization of maxillofacial fractures, and the most common fracture region visualized in this radiography was the body of the mandible. The prevalent cause of maxillofacial fractures was traffic accidents.

\section{Acknowledgements}

We would like to thank Fundação de Amparo à Pesquisa do Estado de São Paulo (Fapesp) 2009/17774-3.

\section{Resumo}

Objetivo: o objetivo deste estudo foi apresentar as causas e a prevalência das fraturas maxilofaciais ocorridas na região de Araraquara durante um período de seis anos. Métodos: informação sobre idade, gênero, etiologia e localização da fratura maxilofacial, bem como o tipo do exame radiográfico foram avaliados. Dados foram obtidos do exame radiográfico e do laudo radiográfico proveniente da disciplina de Radiologia e prontuários da disciplina de Cirurgia e Traumatologia Bucomaxilofacial dos pacientes atendidos com fraturas maxilofaciais entre 2004 e 2009. Uma análise estatística descritiva foi desenvolvida utilizando Epi-Info 3.5.1. Resultados: de um total de 11.728 pacientes atendidos, 407 apresentaram fraturas maxilofaciais. A idade prevalente variou de 21 a 30 anos. Destes, 322 eram homens e 85 eram mulheres (proporção homem/mulher foi de $3,8: 1)$. Radiografia panorâmica $(n=306)$ foi utilizada mais frequentemente para observar fraturas maxilofaciais. Fraturas mandibulares foram frequentes no corpo da mandíbula $(n=127)$ seguida pela sínfise $(n=102)$, e a causa prevalente foi acidentes de trânsito $(n=161)$. Conclusão: mais da metade dos indivíduos afetados eram mais jovens que 40 anos. O corpo da mandíbula foi o local de fratura mais comumente visualizado na radiografia panorâmica para acidentes de tráfego e violência.

Palavras-chave: Fraturas. Epidemiologia. Estudos retrospectivos.

\section{References}

1. Brasileiro BF, Passeri LA. Epidemiological analysis of maxillofacial fractures in Brazil: A 5-year prospective study. Oral Surg Oral Med Oral Pathol Oral Radiol Endod 2006; 102(1):28-34.

2. Al Ahmed HE, Jaber MA, Fanas SHA, Karas M. The pattern of maxillofacial fractures in Sharjah, United Arab Emirates: a review of 230 cases. Oral Surg Oral Med Oral Pathol Oral Radiol Endod 2004; 98(2):166-70.
3. Chrcanovic BR, Abreu MHN, Freire-Maia B, Souza LN. 1,454 mandibular fractures: a 3-year study in a hospital in Belo Horizonte, Brazil. J Craniomaxillofac Surg 2012; 40(2):116-23.

4. Bamjee Y, Lownie JF, Cleaton-Jones PE, Lownie MA. Maxillofacial injuries in a group of South Africans under 18 years of age. Br J Oral Maxillofac Surg 1996; 34(4):298-302.

5. Adebayo ET, Ajike OS, Adekeye EO. Analysis of the pattern of maxillofacial fractures in Kaduna, Nigeria. Br J Oral Maxillofac Surg 2003; 41(6):396-400.

6. Fasola AO, Nyako EA, Obiechina AE, Arotiba JT. Trends in the characteristics of maxillofacial fractures in Nigeria. $J$ Oral Maxillofac Surg 2003; 61(10):1140-3.

7. Oji C. Jaw fractures in Enugu, Nigeria, 1985-95. Br J Oral Maxillofac Surg 1999; 37(2):106-9.

8. Fridrich KL, Pena-Velasco G, Olson RA. Changing trends with mandibular fractures: a review of 1,067 cases. J Oral Maxillofac Surg 1992; 50(6):586-9.

9. Iida S, Hassfeld S, Reuther T, Schweigert HG, Haag C, Klein $\mathrm{J}$, et al. Maxillofacial fractures resulting from falls. J Craniomaxillofac Surg 2003; 31(5):278-83.

10. Laski R, Ziccardi VB, Broder HL, Janal M. Facial trauma: a recurrent disease? The potential role of disease prevention. J Oral Maxilofac Surg 2004; 62(6):685-8.

11. Sakr K, Farag IA, Zeitoun IM. Review of 509 mandibular fractures treated at the University Hospital, Alexandria, Egypt. Br J Oral Maxillofac Surg 2006; 44(2):107-11.

12. Faverani LP, Jardim ECG, Gulinelli JL, Queiroz TP, Panzarini SR, Garcia Júnior IR, et al. Traumas faciais: estudo retrospectivo de 1190 casos na região de Araçatuba. Rev Bras Cir Cabeça Pescoço 2009; 38(1):22-5.

13. Gabrielli MAC, Gabrielli MFR, Marcantonio E, Hochuli-Vieira E. Fixation of mandibular fractures with 2.0-mm miniplates: review of 191 cases. J Oral Maxillofac Surg 2003; 61(4):430-6.

14. Bakardjiev A, Pechalova P. Maxillofacial fractures in Southern Bulgaria - A retrospective study of 1706 cases. J Craniomaxillofac Surg 2007; 35(3):147-50.

15. Bormann KH, Wild S, Gellrich NC, Kokemüller H, Stühmer C, Schmelzeisen R, et al. Five-year retrospective study of mandibular fractures in Freiburg, Germany: incidence, etiology, treatment, and complications. J Oral Maxillofac Surg 2009 ; 67(6):1251-5.

16. Cillo JE Jr, Ellis E 3rd. Treatment of patients with double unilateral fractures of the mandible. J Oral Maxillofac Surg 2007; 65(8):1461-9.

17. Cook HE, Rowe M. A retrospective study of 356 midfacial fractures occurring in 225 patients. J Oral Maxillofac Surg $1990 ; 48(6): 574-8$.

18. Gomes PP, Passeri LA, Albergaria Barbosa J. de. A 5-year retrospective study of zygomatico-orbital complex and zygomatic arch fractures in Sao Paulo State, Brazil. J Oral Maxillofac Surg 2006; 64(1):63-7.

19. Hächl O, Tuli T, Schwabegger A, Gassner R. Maxillofacial trauma due to work-related accidents. Int J Oral Maxillofac Surg. 2002; 31(1):90-3.

20. He D, Zhang Y, Ellis E. Panfacial fractures: analysis of 33 cases treated late. J Oral Maxillofac Surg 2007; 65(12):245965 . 
21. Iida S, Kogo M, Sugiura T, Mima T, Matsuya T. Retrospective analysis of 1502 patients with facial fractures. Int J Oral Maxillofac Surg 2001; 30(4):286-90.

22. Motamedi MHK. An assessment of maxillofacial fractures: a 5-year study of 237 patients. J Oral Maxillofac Surg 2003; 61(1):61-4.

23. Ogundare BO, Bonnick A, Bayley N. Pattern of mandibular fractures in an urban major trauma center. J Oral Maxillofac Surg 2003; 61(6):713-8.

24. Roode GJ, van Wyk PJ, Botha SJ. Mandibular fractures: an epidemiological survey at the Oral and Dental Hospital, Pretoria. SADJ. 2007; 62(6):270,272-4.

25. Scariot R, Oliveira IA, Passeri LA, Rebellato NLB, Müller PR. Maxillofacial injures in a group of Brazilian subjects under 18 years of age. J Appl Oral Sci 2009; 17(3):195-8.

26. Sirimaharaj W, Pyungtanasup K. The epidemiology of mandibular fractures treated at Chiang Mai University Hospital: a review of 198 cases. J Med Assoc Thai 2008; 91(6):868-74.

27. Subhashraj K, Nandakumar N, Ravindran C. Review of maxillofacial injuries in Chennai, India: A study of 2748 cases. Br J Oral Maxillofac Surg 2007; 45(8):637-9.

28. Vetter JD, Topazian RG, Goldberg MH, Smith DG. Facial fractures occurring in a medium-size metropolitan area: recent trends. Int J Oral Maxillofac Surg 1991; 20(4):214-6.

29. Batista AM, Ferreira FO, Marques LS, Ramos-Jorge ML, Ferreira MC. Risk factors associated with facial fractures. Braz Oral Res 2012; 26(2):119-25.

Andréa Gonçalves

Departamento de Diagnóstico e Cirurgia

Faculdade de Odontologia de Araraquara -

Unesp

Rua Humaitá, 1680 - 14.801-903

Araraquara-SP, Brasil

Fone: +55-16-3301-6380

Fax: +55-16-3301-6359

E-mail: andreag@foar.unesp.br

Recebido: 26/02/2013. Aceito: 22/04/2013. 